(c) The Author(s), 2021. Published by Cambridge University Press. This is an Open Access article, distributed under the terms of the Creative Commons Attribution licence (https://creativecommons.org/licenses/by/4.0/), which permits unrestricted re-use, distribution, and reproduction in any medium, provided the original work is properly cited. doi:10.1017/S1474746421000506

\title{
Diversifying the Social Policy Curriculum: A Collaborative Approach
}

\author{
Barbara Adewumi* (1) and Lavinia Mitton**
}

*University of Kent, Canterbury, UK

Email: B.Adewumi-282@kent.ac.uk

**School of Social Policy, Sociology and Social Research, University of Kent, Canterbury, UK Email: L.Mitton@kent.ac.uk

This article offers a practical methodological 'toolkit' for creating more diverse reading lists for social policy teaching. It reports on the findings of the award-winning 'Reading List Diversity Mark Project', carried out at the University of Kent in 2018-20, which investigated how many Black, Asian and other ethnic minority authors were included on undergraduate reading lists. Through the application of critical race theory (CRT), we argue that inclusive curricula matter. We then analyse the reasons for the marginalisation of race and ethnicity in the social policy curriculum. A distinctive aspect of the project was the nature of our staff-student collaboration and we discuss how this shaped its design and outcomes. We argue that our approach could be implemented at other institutions and conclude with suggestions about how to achieve a more diverse social policy curriculum.

Keywords: Decolonising, curriculum, reading lists, race, critical race theory.

\section{Introduction}

This action and practice article offers a 'how to' guide for academics, students and librarians who want to diversify their curricula and explore the relationship between race and ethnicity, student engagement and belonging in their subject area. It engages with the following aspects of the Social Policy Association's action plan for 'race' and ethnicity in social policy (SPA, 2020): encouraging and supporting the teaching of issues related to 'race' and ethnicity in higher education institutions (HEls); identifying and signposting teaching materials that could be useful to members to expand the teaching of 'race' and ethnicity; and encouraging HEls to undertake an effective audit of the balance of the content of each course.

The campaign to 'decolonise' the curriculum encompasses a multitude of interpretations and strategies which aim to dismantle whiteness and forms of systemic racism in educational institutions. Reimagining and implementing an inclusive curriculum do present structural challenges, but we believe that much of the solution emanates from listening and collaborating with students of colour to examine the extent to which Eurocentric epistemological canons of knowledge can be readdressed and a fairer representation of global knowledge can be appreciated by all within social sciences. In this article, we briefly describe a toolkit called the Reading List Diversity Mark (University of Kent, n.d.). We answer the call of Bhambra et al.'s Decolonising the University (2018) 
by offering resources for students and academics to challenge and resist coloniality inside the classroom and providing a tool that could potentially lead to radical pedagogical, disciplinary and institutional change. We draw on our own experiences and Critical Race Theory (CRT) to outline the Diversity Mark initiative's strengths and challenges. Specifically, we argue that by using a collaborative action approach the Diversity Mark brings with it four important virtues: first, the student voice is heard; secondly, it shows that a diverse curriculum matters; thirdly, it is proactive towards narrowing the awarding gap; and fourthly, it contributes towards institutional goals such as widening participation and equality strategies. However, at the same time, there are three principal tests to its implementation that all need be carefully addressed: scepticism by some staff, encountering uncomfortable conversations, and resourcing.

In the remainder of this article, we first map out the controversies and theories that guided the project. We then describe how the Diversity Mark initiative came about. Finally, we go into some detail about how it was implemented and our findings with respect to the subject of social policy.

\section{Why does diversity on reading lists matter?}

There are at least four reasons why having a greater diversity of authors on reading lists matters. First is the number of voices across HE arguing for the decolonisation of the curriculum, such as Liyanage (2020) and in the report by Runnymede (Alexander and Arday, 2015), an independent race equality charity think tank based in the UK. Movements led by students gained significant traction in the years 2015-17, notably \#RhodesMustFall, \#liberatemydegree and 'Why is My Curriculum White?'. The Black Lives Matter movement that was created in 2013 has increased the pressure on all areas of UK society to confront its colonial legacy. Diversifying reading lists can be viewed as one component of the agenda to decolonise the curriculum, towards a process of unlearning and relearning knowledge.

Secondly, from the perspective of the theory of knowledge, diverse reading lists matter, according to Hall and Tandon (2017), because:

what is generally understood as knowledge in the universities of our world represents a very small proportion of the global treasury of knowledge. ... The epistemologies of most peoples of the world, whether Indigenous or excluded on the basis of race, gender or sexuality are missing (Hall and Tandon, 2017: 7).

Thirdly, the persistent absence of BAME scholarship has informed a growing body of research that asserts that there is a causal link between the 'whiteness' of the curriculum and the awarding gap ${ }^{1}$ and students' sense of belonging (Broecke and Nicholls, 2007; Singh, 2011; Mountford-Zimdars et al., 2015; Richardson, 2015; Mcduff et al., 2018; UUK and NUS, 2019; Arday, 2020). UUK and NUS (2019) argued the curriculum is central to the experiences and progression of BAME students. Stevenson's (2012) comprehensive report, which included surveys with university lecturers and BAME students in the UK's HEls recommended that reading materials and theoretical input should include nonwhite, non-Western perspectives.

Although its causes are complex, and it is important to avoid 'reductive or simplistic explanations' (HEA, 2008), diversifying reading lists can nevertheless be tried as a 
proactive strategy to narrow the white-BAME 'awarding' gap in higher education. The awarding gap is a key performance indicator for universities in England because the regulator, the Office for Students, has set universities the target to 'eliminate the "unexplained" gap in degree outcomes (1sts or 2:1s) between white students and black students by 2024-25' (OfS, 2018). Fourthly, the promotion of a diverse curriculum is also allied to compliance with equalities legislation such as the Equality Act 2010, the Public Sector Equality Duty, and the Higher Education and Research Act 2017; and the Athena Swan Charter award, which is a requirement of several large research funding bodies. In addition, many universities have their own goals to develop an inclusive curriculum as part of their internal widening participation and equality and diversity strategies, such as aiming for the Race Equality Charter.

Turning to the place of reading lists in pedagogy, there is a dearth of literature, although Stokes and Martin (2008) Brewerton (2014), Siddall and Rose (2014) and Bird and Pitman (2020) are exceptions. We do know that reading lists are an important representation of the legitimised ideas, theories and perspectives that dominate within a discipline. Furthermore, they influence students' reading choices, acting as a compass that students may utilise to traverse their academic terrain. In theory, reading lists that positively represent the diversity of the student body also improve engagement because students need to see themselves in course texts. It can be hypothesised that this is because diverse texts dismantle the prevailing stereotype of the white and predominately male social scientist, encouraging all students to continue engaging in the subject, regardless of group membership. A minor change to provide opportunities for students to see 'people like me' in the curriculum could make a major change to the way a student, or a group of students, responds to a course (Thomas and Jivraj, 2020).

The Diversity Mark contributes by adding representation to the curriculum, rather than by deep revision to racial literacy, and fundamentally challenging what constitutes knowledge and wisdom. But we argue that revising a reading list to include alternative or marginalised perspectives is one of many strategies that can be employed to challenge the status quo. As De Sousa Santos (2014) has argued, the goal does not have to be to throw the prevailing literature into the dustbin of history, but rather to include 'Eurocentric critical tradition in a much broader landscape of epistemological and political possibilities' (2014: 44). Joseph-Salisbury et al. (2020) found staff sometimes argue that they have incorporated one or two key thinkers of colour into their reading lists. Their thinking tended to be that they had done all they could by doing so and did not have time to rethink their pedagogical lenses more substantially than this. This toolkit recognises that a curriculum is more than just reading lists. But it is a good place to start the process.

\section{'Race' and ethnicity in the social policy curriculum}

Whilst the study of social policy traditionally has been shaped by the post 1945 welfare state, the Subject Benchmark Statement for Social Policy (QAA, 2019), although not prescriptive, affirms that 'race' and ethnicity are part of the contemporary curriculum. It has also previously been observed that social policy should lend itself well to a decolonised curriculum because BAME inequalities in intersection with other social divisions relate to almost all social policy themes (Craig et al., 2019). Recent UK injustices, 
such as the Windrush Scandal, Grenfell, and the high death rates from Covid-19 among BAME groups, to name a few, demonstrate why students need to understand the deep-rooted colonial links which have disadvantaged BAME groups' lives. Given the economic impact and social complexities of multicultural communities it should hardly be difficult to find social policy texts that speak to BAME students and incorporate these into teaching. However, previous reports into teaching at UK HEls in social policy (Craig et al., 2019), sociology (Joseph-Salisbury et al., 2020) and by the Royal Historical Society (RHS, 2018) together suggest some common problems. We consider these in the remainder of this section.

Craig et al. (2019) found very narrow attention to 'race' and ethnicity. Where they were covered, it was often in restricted areas of discussion, such as migration, rather than the impacts of racism within wider public policy. Although these findings were not definitive, it was apparent that social policy at undergraduate level was 'white male and stale'. BAME scholarship was virtually absent with a very small number of white authors contributing strongly to the field. This finding was supported by the highly critical report from the RHS (2018), which concluded that the history curriculum is seen as simply not reflecting the diversity of UK life. Most of the Black history taught is American history, apart from the 'Windrush Myth', and not our own global interactions with Africans on three continents (Olusoga, 2018). Similarly, a report for the British Sociological Association (Joseph-Salisbury et al., 2020) found that where race was taught, the focus was often limited to England, although sometimes the United States, and on Black and Asian populations, with little attention to 'whiteness as a raced category'. Craig et al. (2019) discovered a lack of specifically social policy modules addressing BAME issues. Even then, 'race' and ethnicity often seemed to be taught as an add-on, or solely a specialist module, rather than a fundamentally integrated part of the curriculum. Similarly, Joseph-Salisbury et al. (2020) found there is a definite lack of integration of 'race' and ethnicity into core reading lists. This can lead to positioning the study of race and ethnicity as a niche interest with only tangential implications for the study of social policy. Whilst many courses surveyed by Craig et al. (2019) incorporated modules with race content from other disciplines, this approach itself risks missing out a specifically social policy focus and seeming to 'outsource' teaching on such to sociology.

Both Senior (2012) and Craig et al. (2019) discussed how BAME students become disengaged because the curriculum is not seen as relevant to their interests and experience. Singh (2011) also has advocated the integration of components on social justice and global citizenship into all courses as a way to improve BAME students' engagement, although this must be implemented in such a way so that a focus on social problems or victimisation does not dominate and perpetuate negative stereotypes. At the time of writing, the University of Kent and Transforming Access and Student Outcomes (TASO, 2021) were evaluating the Diversity Mark intervention because of the absence of conclusive research evidence one way or the other that having additional content specifically on 'race' has any significant impact on BAME student intake onto social policy degrees or contributes to the retention and attainment of these students.

Undoubtedly, bringing 'race' and ethnicity into the core concern of social policy will take a long time to resolve, but more immediate changes are within the gift of those teaching social policy; and diversifying reading lists is one such intervention. 


\section{Theoretical framework}

Our conceptual framework was taken from CRT. By directly addressing structural inequalities, CRT places a spotlight on race to illuminate how systemic forms of racism within education have silenced the voices and epistemological scholarship of authors of the global South, particularly erasing the importance of social theory within the canon of social sciences (Solórzano and Yosso, 2002; Ladson-Billings and Tate, 2006; Delgado and Stefancic, 2017). The more indigenous styles of knowing, which Ladson-Billings (2003) calls 'ethnic epistemologies', have all-too-often become subordinated. Yet as LadsonBillings (Ladson-Billings, 1998) has argued, 'there are well-developed systems of knowledge, or epistemologies, that stand in contrast to the dominant Euro-American epistemology' (Ladson-Billings, 1998: 258). Following the key tenets of CRT, we applied the method of counter-storytelling (Ladson-Billings, 1998; DeCuir and Dixson, 2004; Parker and Villalpando, 2007), collating unique narratives of people of colour which often shone a light on the dominant ideology of whiteness that perpetuates racial stereotypes. This acted as a framework that contextualised the racialised and subordinate experiences of marginalised groups in HE. Another key tenet of CRT is that systemic forms of racism further 'colour blindness', a mechanism that allows people deliberately and routinely to deny racialised relationships and practice racialised policies that perpetuate social inequity. By depicting their own cultures and practices as race-neutral and meritocratic, universities advance the notion that students are learning in 'post-racial' institutions, where reading lists are colour blind. As Mirza (2018) has argued: 'by adopting "colourblind" and "complacent" bureaucratic approaches, universities can claim to be doing something, while really doing nothing at all to change the status quo' (2018: 7).

\section{The project institution}

The University of Kent has seen a substantial increase in the number of students from lower participation groups and neighbourhoods over the last decade. By 2020 the university had 14,500 full-time and 800 part-time undergraduates. Forty-three per cent identified themselves as from any BAME group, 18 per cent were Black and 12 per cent were Asian. Among the undergraduates doing a degree in social policy, sociology, criminology or social work in 2020, 41 per cent of Canterbury students and 63 per cent of Medway students were from any BAME group. Half of these were of African descent. In 2020, the vast majority of the university of Kent's undergraduates came from London (27 per cent) or the rest of the South East (40 per cent). The initiative we describe in this article focused on the promotion of diverse reading lists to help meet the needs of this changing student population.

\section{The Reading List Diversity Mark}

The Reading List Diversity Mark is an award available to modules across all the subjects taught at the University of Kent. Those that have received the award have a logo displayed next to them on the online reading list system in use at the university (see Figure 1). This initiative aims to recognise best practice in diversifying reading lists, and to make recommendations where practice falls short of the required standard for the award. It offers academic schools a visualisation of their respective data metrics on diversity in their 




Figure 1. The Diversity Mark logo

reading lists. It is a cross-departmental collaboration between colleagues from the library, academic departments, the students' union and student researchers working as a team to encourage reflection on the demographic makeup of reading lists and to stimulate conversations on how we can diversify reading lists to represent a more universal collection of knowledge. The Diversity Mark is underpinned by a toolkit that supports academic departments to incorporate more diverse schools of thought and authors within their reading lists. This article explains this toolkit so that others can adopt or adapt it.

The Diversity Mark transpired as a direct response to the student union's 'Diversify My Curriculum' campaign and its BME student voices report (Kent Union, 2016), which echoed student voices across $\mathrm{HE}$ in its recommendation that 'The University should aim to diversify the content of its curriculum and make it more inclusive, starting with reviewing curricula to ensure that a range of ideas and academic thoughts are represented'. It brought to light that students believed the curriculum was centred on Eurocentric ideals, with a lack of BAME authors, and they felt this had an impact on their studies because both BAME and white students were missing out on alternative discourses (Kent Union, 2016). Another student-led initiative was Kent Law School's Decolonise the Curriculum Project (DtCP). This inspired a chain reaction of events across the university (Jivraj, 2020). Also motivating the Diversity Mark was the university's strategy to narrow the white-BAME awarding gap. Finally, it was allied to the university's overall widening participation and equality and diversity strategies. The primary objectives were to investigate the extent to which reading lists' demographic composition impacted on students' interest and engagement with the curriculum, and to examine the extent to which pedagogic interventions can be operationalised through reading lists in order to gain an understanding of student and teaching staff's perceptions and expectations of them.

By reviewing social policy reading lists and analysing how they were selected and how the content was taught, the Diversity Mark initiative facilitates honest conversations about ways that the reading could project a fairer representation of BAME scholarship. The impact of this ongoing project is yet to be evaluated. At this stage it can be viewed as an 
example of a 'do something' proactive, pragmatic approach and the commitment that the university has to creating an enriching learning environment for its students towards promoting equality and diversity in academia. In what follows, we describe our methodology, which involved all of the following: a desk-based review of reading lists; focus groups with students and staff; and interviews with module convenors. The intention is to offer a toolkit, blueprint or recipe that social policy colleagues can adapt. Although in this article we discuss the findings of the Diversity Mark initiative in relation to social policy, it can readily be adapted to any subject area.

\section{Review of reading lists}

In this section we discuss our findings from ten Stage 1 modules offered by the School of Sociology, Social Policy and Social Research (SSPSSR) in 2018-2020. Large compulsory introductory first-year undergraduate modules were chosen for this exercise to reflect larger BAME student groups registered on these core modules, some of whom were then recruited to participate in student focus groups. The key research question was: to what extent are reading lists composed of diverse authorship? We hypothesised that the sources would be predominantly white, European and male.

Adopting a 'quality mark' approach to the curriculum raises questions about who should set and judge quality. We were convinced that to create sustainable change we needed work with students. We devised the Diversity Mark project 'reading list review', a process whereby staff and students, in partnership, would engage in a collaborative, power-sharing relationship to explore the extent to which the contents, concepts and context of a module's reading lists were representative of diverse knowledge systems. We employed two students as project officers. They became change actors and co-producers of knowledge having been fully involved in the development of the project from the onset to its dissemination of findings. In turn, it was a group consisting of both staff and students who decided which modules should be awarded the Diversity Mark.

All items on the reading lists had been categorised by the module convenor as either: Core (Must Read), Recommended (Should Read), Background (Could Read), or Suggested for Student Purchase. Our approach was to quantify the number of readings by globally diverse authors labelled 'Core (Must Read)', both to create a conversation about what constitute 'must read' texts for the social policy curriculum and because we know that these are the ones students are most likely to read. While checklists and toolkits have become a feature of approaches to decolonise the curriculum, to date, there has been an absence of a methodology to guide such a reading list review. In the absence of a robust methodology and literature to guide such analysis (Piscioneri and Hlavac, 2013), the reading lists were analysed by means of desk-based research, in which the ethnic identity of the author was obtained from mediums within the public domain. For example, internet was used to search for: academic webpages; author biographies; author images; Google books; social media presence; academic institutions; publisher's webpages; conference and workshop papers. The data was inputted into a spread sheet. This contributed to developing a profile of the author. More weight was given to an author's own biography. We counted the number of diverse authors on reading lists with the acknowledgement that numbers have no objective reality and are constrained within the policies and frameworks of meaning that create them. We adopted a QuantCrit perspective because it seeks to 'apply CRT understandings and 
insights wherever quantitative data is used in research and/or encountered in policy and practice' (Gillborn et al., 2018: 169). QuantCrit foregrounds the need to think critically about how the realities of society are shaped by race/gender inequality, which is deeply embedded in everyday realities. This is important, as data are neither objective nor colour blind. We used the term 'diverse' in a similar manner to Hall and Tandon (2017) to represent an ecosystem inclusive and equally representative of traditionally excluded groups such as racialised groups, Indigenous peoples, those generally excluded on the basis of gender, class or sexuality, as well as from their white counterparts.

\section{Findings and lessons}

Our findings reflected those of Craig et al. (2019) that most of the social policy teaching on race was not at the core, even though some topics within some modules covered the unequal distribution of resources by the state which affects a significant proportion of nonwhite segments of the population. Our findings suggested reading lists in social policy at the University of Kent (as they stood at that time) did not present a diverse range of scholars and perspectives. Across all modules, very similar findings emerged. We found that reading lists in social policy predominantly were comprised of white, European, male authors. Specifically, 69 per cent of all authors were white men and 27 per cent of all authors were white women. Just 3 per cent were BAME women and only 2 per cent were BAME men. In one of the largest social policy modules, white men made up 74 per cent of the total, while white women were 25 per cent of authors, there were no BAME male authors and only one per cent BAME female authors. Very few voices from the global South were heard. We found that where lesser-known BAME scholars were recommended, they were marginalised in 'additional' reading. Single-authorship works by white males dominated the reading lists. The BAME female authors who appeared tended to be co-authors. The evident exclusion of BAME scholars from reading lists is an ongoing problem of the historical epistemic injustice practices embedded in Western and Eurocentric scholarship and colonial- and imperialistlinked structures of knowledge production. The interplay between power and knowledge means recommended reading tends to consist of annual renewal of essential readings, and in-built hierarchies and expectations by external moderators, which all constitute homogenous institutional implicit forms of bias (Bhambra et al., 2018). This may suggest implicit bias in the discipline itself or more comfortable and familiar access to those readings. Consequently, there has been a strong call by decolonising campaigns to recognise niche publications that bring the complexities of intersectional inequalities and critical thought to the table, rather than tired reliance on the multiple editions of core textbooks.

Reductivism and tokenism are potential dangers of a 'quality mark' approach and staff and students of colour did question whether it was just a 'tick box' exercise. Indeed, some staff resisted reviewing their reading lists on the grounds that adding a few textbooks and articles by authors from the global South would be mere tokenism. However, the outcome was more far-reaching than that. The intention was to create a widespread momentum for change by stimulating uncomfortable conversations about the sheer whiteness of the curriculum and the lack of cultural sensitivity within pedological episteme taught predominantly by white academics. 


\section{Partnership with students}

Focus groups were held with students $(N=16)$ by the project officers in autumn 2019 in order better to appreciate their perceptions of the value of a reading list. The inclusion criteria for participants were: i) they were undergraduate students studying a social science subject at the University of Kent; and ii) they self-defined as African, Afro Caribbean, Mixed Black and White, or any other minoritised ethnic group. The participants were asked about their initial impressions when they saw their reading lists during the first six weeks of their degree. In addition, since this toolkit was developed with students, the project officers were encouraged actively to contribute their knowledge and expertise in the form of a reflection on their experiences. This departed from the notion of students as mere data sources and is aligned with the concept of a student-staff partnership that stimulates a way of thinking, engaging and working in partnership with students and staff to contribute different, but equally valuable, knowledge and expertise to research processes.

\section{Findings and lessons}

We employed a CRT analysis of the focus group transcripts to highlight the role of storytelling as an analytical tool to interrogate the centrality of race and provide counternarratives. Three themes that emerged from this process were students' perceptions of: 1) the importance of the demographic characteristics of authors in (dis)engaging with the reading lists; 2) the purpose of reading lists; and 3) their ability to challenge concepts and ideas. We next discuss these in turn.

First, BAME students found representation on modules that deal explicitly with race to be crucial; even on those that do not directly address this topic, representation had a direct effect on whether they felt able to progress in that field of study. As one participant remarked, this project:

has enabled me to see that scholars and academics from around the globe are contributing to research and this reinforced in me that academic status is attainable for people of colour.

Nevertheless, some participants believed that the authors on their reading list would inevitably be primarily white men. This is symptomatic of the centrality of racism, where whiteness and white privilege are reinforced and continue to be self-perpetuated. Participants stated that gender, sexuality, class and social status were the social divisions given the greatest attention, while race and ethnicity were only slightly touched on in seminars and lectures and that they were presumed to accept that we now live in a 'postracial' society. Students' views also showed the importance of a sense of belonging and demonstrated the need for - and impact of - decolonisation work:

I don't want to learn about oppression in a framework that is still oppressing. I want to learn about it in a framework that liberates my brain ... that raises me above it.

Secondly, we found a common concern amongst participants related to the volume of reading that they were expected to do. This was indicative of a lack of understanding of the purposes of reading lists at degree level. A project officer reflected that: 
I had a typical student mind-set, where looking at the reading list was not my main priority. I did not really engage with the reading list nor give it any real thought.

Thirdly, the information from participants provided clear evidence that students are heavily dependent on their lecturers and what they recommend as essential reading. Taken together, the feedback from the focus groups suggested that diversifying reading lists would be well-received by all students.

\section{Engagement with teaching staff}

We sought to understand the engagement with reading lists by staff as well as students. Therefore, each convenor was sent bespoke data about their module's reading list review. Some staff did not initially see the value of students of colour advising 'them' about the quality of their reading lists and became defensive at the prospect of non-academic staff questioning their academic judgement. They were given time to reflect and invited to respond to a short feedback qualitative survey by email on a voluntary basis to gain their perspectives on the data. In all cases, they observed that the overwhelming majority of their core/compulsory reading was by British or European white male authors. Follow-up interviews were conducted with five convenors in 2019-2020. A critical reflexive framework was used to construct the interview with CRT as a theoretical lens (the full interview guide is available from the authors). Convenors were given the opportunity to honestly question their own assumptions and their perceptions of their reading lists in a non-threatening way. This encouraged empowering conversations about how staff can move forward with broadening reading lists, better to engage the BAME cohort present in their classrooms.

\section{Findings and lessons}

First, we found that there was an overall admission from convenors that they needed to do more to introduce a wider range of global scholars in their reading lists and that they should make a more conscious effort to embed this in their teaching practices. This comment was typical:

I would say diversity and demographic difference ARE represented in the taught material in class, but the reading lists are very Eurocentric. This project has been very illuminating for me as a social policy academic, and has made me sensitive to issues of representation on this module.

Secondly, as noted elsewhere, there existed the perception that reading lists have their place, but are not the answer to the white-BAME awarding gap. For example, this convenor emphasised that for too long students have been seen as the problem (when taking a deficit model approach) and that identity politics (political alliances fighting against oppression based on one's identity) has been used as a smoke screen to avoid the real issues that are facing academia:

While I agree that representation of BAME scholars in the curriculum is important for the wider task of decolonising the academy, it's important not to conflate identity politics with structural barriers to attainment. 
In other words, ironically, identity politics had become more popular a discussion than liberating the curriculum itself. The following case study provides one convenor's personal experiences of teaching race and ethnicity whilst being a racial outsider (white middle class male). He described how he navigated his way towards understanding his BAME students' sense of belonging and the limitations and practical use of reading lists when it came to representation. He was very conscious that social policy reading lists were inexcusably too white! He commented:

When it comes to social policy and race there are no universities doing it well. In social policy literature, there tends to be more on gender than there is on race. I would be surprised if I were to find any Black female authors.

He admitted a sense of discomfort about the dominance of white authorship in social policy taught by only white lecturers and wished for a diverse range of teaching staff in the discipline so that he could exchange ideas: 'I haven't got an ethnic minority social policy colleague to draw on [for the week on race and social policy]'. He actively sought out the intellectual capital of Black and Asian and female colleagues who possess global knowledge and research interests in gender, CRT, post colonialism and structural inequalities because he himself has found it frustratingly difficult to locate resources that provide a deeper insight about the impact of social policy on ethnically diverse lived experiences. He remains concerned about the disconnect that this gap in knowledge causes in social policy. But he described how he can tap into another rich resource of knowledge - students of colour:

When I teach the seminar on race, I will encourage students to share their experiences because so many have experiences intersecting between the welfare state and race that I don't have.

However, in the feedback surveys and interviews staff overall emphasised the practical obstacles to putting diversifying reading lists into practice, despite the expressed desire to do so. For example, when a reading list has been used for some time and previous students have not questioned it, some staff might argue that they do not see the need to diversify it. But the biggest obstacle in our experience is the perennial problems familiar to HE staff of competing priorities and workload recognition. Consequently, because of the extra amount of work involved some staff might not be willing to participate. Therefore, the majority of our funding was allocated employing project officers to carry out the reading list review. To review one twelve-week module including analysis, writing up and producing infographics took approximately seventy hours. To overcome resistance, we prepared the environment to be right for challenging conversations: for example, by identifying allies and supporters in the university. It proved necessary to educate and raise awareness of the need to diversify reading lists to all staff from the outset, to marshal feedback from students, and to present staff with their Diversify Mark review report. We found that the 'peg' of the potential impact on BAME student attainment and engagement can bring colleagues on board, as can the importance of this work being recognised at an institutional level.

\section{Conclusion}

In terms of outcomes which will improve student experience, we do not wish to pre-judge what these might be. The evaluation stage of the project will explore whether the Diversity 
Mark improved the student experience and helped towards reducing the white-BAME awarding gap. However, what has emerged so far is that some module convenors have come to the realisation that when compiling reading lists, they should take responsibility, they should listen to their BAME students' counter-stories.

Since understanding social inequality is a central endeavour of social policy research, diversifying the voices heard to include BME and alternative knowledge sources should be relatively achievable. Indeed, there is already a wider movement underway for consulting service users in how they are represented in social policy, rather than 'doing it to' them. Including global South perspectives can provoke students to consider how social policies produce and sustain racialised inequalities. Evidence from sources often unheard in Western contexts can help students see how the colonial legacy has influenced policymaking and its subsequent impacts on marginalised groups and on society as a whole. Also on an optimistic note, the staff-student collaborative aspect of the Diversity Mark project has demonstrated the potential for the social policy curriculum to take an epistemic shift further towards cultivating critical thinking, helping students to appraise the usefulness and limitations of any knowledge sources, emphasising students' capacity to be open to multiple and different standpoints, and to be able to challenge established hegemonic standpoints.

On the other hand, for module convenors, an immediate hurdle to diversifying the background of the authors on undergraduate reading lists is lack of knowledge about other reading that they could introduce, or the absence of a tradition of using forms of knowledge other than journals or core textbooks, such as personal narratives. Diversifying the social policy curriculum in the broader sense of incorporating evidence from sources often omitted in Western contexts presents some further obstacles. One is that the study of social problems, policies and the policy-making process is often geographically contextspecific. At undergraduate level it is often UK-specific, focused largely on England. This limits the perceived relevance of global South knowledge. Whilst comparative social policy is a staple of undergraduate social policy programmes, and a potential space to incorporate knowledge from the global South, we argue that responsibility for diversifying the curriculum should not be delegated to comparative policy studies. More fundamentally, diversifying authors on reading lists is a starting point, but cannot undo social policy's roots in social administration, at one time a primarily British imperial administrative project, with epistemes intrinsically situated in Western ideas and hierarchies of 'social progress' that have historically marginalised, omitted, or repressed other worldviews and sources of knowledge.

It may be an uncomfortable journey for some to reflect on their position of privilege and assess how they can move to anti-racist teaching practices. This is both challenging and difficult work that will disrupt what has long been a deeply entrenched and complacent space for some, but one which needs to be dismantled and reconfigured.

\section{Acknowledgements}

The Reading List Diversity Mark was a collaboration among several colleagues at the University of Kent including Evangeline Agyeman, Collins Konadu Mensah, Emma MiresRichards, Sarah Field, Dave Thomas, Patrice Mighton, Nain Wassamba-Wabelua, Tore Shortridge and Aisha Alabi. 


\section{Notes}

1 The 'BAME degree awarding gap' (also known as the 'attainment gap') is the difference between the proportion of white UK students awarded first-class or 2:1 degrees compared to Black, Asian and Minority Ethnic UK students.

\section{References}

Alexander, C. E. and Arday, J. (eds.) (2015) Aiming Higher: Race, Inequality and Diversity in the Academy, London: Runnymede Trust.

Arday, J. (2020) 'Fighting the tide: understanding the difficulties facing Black, Asian and Minority Ethnic (BAME) doctoral students' pursuing a career in Academia', Educational Philosophy and Theory, DOI:10.1080/00131857.2020.1777640.

Bhambra, G. K., Gebrial, D. and Nişancioğlu, K. (eds.) (2018) Decolonising the University, Chicago: Pluto Press.

Bird, K. S. and Pitman, L. (2020) 'How diverse is your reading list? Exploring issues of representation and decolonisation in the UK', Higher Education, 79, 5, 903-20.

Brewerton, G. (2014) 'Implications of student and lecturer qualitative views on reading lists: a case study at Loughborough university, UK', New Review of Academic Librarianship, 20, 1, 78-90.

Broecke, S. and Nicholls, T. (2007) Ethnicity and Degree Attainment, Munich Personal RePEC Archive, 2011.

Craig, G., Bankole, C., Ali, N. and Qureshi, I. (2019) The Missing Dimension: Where is 'Race' in Social Policy Teaching and Learning?, York: Social Policy Association.

DeCuir, J. T. and Dixson, A. D. (2004) "'So when it comes out, they aren't that surprised that it is there": using critical race theory as a tool of analysis of race and racism in education', Educational Researcher, 33, 5, 26-31.

Delgado, R. and Stefancic, J. (2017) Critical Race Theory: An Introduction (Vol. 20), New York: NYU Press.

De Sousa Santos, B. (2014) Epistemologies of the South: Justice against Epistemicide, London and New York: Routledge.

Gillborn, D., Warmington, P. and Demack, S. (2018) 'QuantCrit: education, policy, 'big data' and principles for a critical race theory of statistics', Race Ethnicity and Education, 21, 2, 158-79.

Hall, B. L. and Tandon, R. (2017) 'Decolonization of knowledge, epistemicide, participatory research and higher education', Research for All, 1, 1, 6-19.

Higher Education Academy (HEA) (2008) Ethnicity, Gender and Degree Attainment Project Final Report, York: HEA.

Jivraj, S. (2020) 'Decolonizing the academy - between a rock and a hard place', Interventions, 22, 4, 552-73.

Joseph-Salisbury, R., Ashe, S., Alexander, C. and Campion, K. (2020) Race and Ethnicity in British Sociology, Durham: British Sociological Association.

Kent Union (2016) BME Student Voices Project: A Report on the Experiences of Black and Minority Ethnic (BME) Students at The University of Kent, Canterbury: Kent Union.

Ladson-Billings, G. (1998) 'Just what is critical race theory and what's it doing in a nice field like education?', International Journal of Qualitative Studies in Education, 11, 7-24.

Ladson-Billings, G. (2003) 'It's your world, I'm just trying to explain it: understanding our epistemological and methodological challenges', Qualitative Inquiry, 9, 1, 5-12.

Ladson-Billings, G. and Tate, W. F. (2006) 'Toward a critical race theory of education', in A. D. Dixson, C. K. Rousseau, C. R. Anderson and J. K. Donnor (eds.), Critical Race Theory in Education: All God's Children Got a Song, Chichester: Taylor and Francis.

Liyanage, M. (2020) Miseducation: Decolonising Curricula, Culture and Pedagogy in UK Universities, HEPI Debate Paper 23.

Mcduff, N., Tatam, J., Beacock, O. and Ross, F. (2018) 'Closing the attainment gap for students from black and minority ethnic backgrounds through institutional change', Widening Participation and Lifelong Learning, 20, 1, 79-101. 
Mirza, H. S. (2018) 'Racism in higher education: 'what then, can be done?', in J. Arday and H. Mirza (eds.), Dismantling Race in Higher Education, Basingstoke: Palgrave Macmillan, 3-23.

Mountford-Zimdars, A. K., Sanders, J., Jones, S., Sabri, D. and Moore, J. (2015) Causes of Differences in Student Outcomes, London: Higher Education Funding Council for England.

Office for Students (OfS) (2018) 'Official statistic: key performance measure 4', Office for Students, https:// www.officeforstudents.org.uk/about/measures-of-our-success/participation-performance-measures/gapin-degree-outcomes-1sts-or-21s-between-white-students-and-black-students [accessed 12.11.2020].

Olusoga, D. (2018) 'Why black history month matters', Charitable Trust, https://charity.hopenothate.org.uk/ news/black-history-month-matters [accessed 16.11.2020].

Parker, L. and Villalpando, O. (2007) 'A race(cialized) perspective on education leadership: critical race theory in educational administration', Educational Administration Quarterly, 43, 5, 519-24.

Piscioneri, M. and Hlavac, J. (2013) 'The minimalist reading model: rethinking reading lists in arts and education subjects', Arts and Humanities in Higher Education, 12, 4, 424-45.

Quality Assurance Agency (QAA) (2019) Subject Benchmark Statement: Social Policy, London: Quality Assurance Agency for Higher Education.

Richardson, J. T. E. (2015) 'The under-attainment of ethnic minority students in UK higher education: what we know and what we don't know', Journal of Further and Higher Education, 20, 2, $278-91$.

Royal Historical Society (RHS) (2018) Race, Ethnicity and Equality in UK History, London: Royal Historical Society.

Senior, N. (2012) Exploring the Retention and Attainment of Black and Minority Ethnic (BME) Students on Social Policy Pathways in Higher Education, York: The Higher Education Academy.

Siddall, G. and Rose, H. (2014) 'Reading lists-time for a reality check? An investigation into the use of reading lists as a pedagogical tool to support the development of information skills amongst foundation degree students.' Library and Information Research, 38, 118, 52-73.

Singh, G. (2011) A Synthesis of Research Evidence. Black and Minority Ethnic (BME) Students' Participation in Higher Education: Improving Retention and Success, York: Higher Education Academy.

Social Policy Association (SPA) (2020) 'Action plan on 'race' and ethnicity in social policy', 1 June, http:// www.social-policy.org.uk/spa-reports/spa-bame-action-plan/ [accessed 14.07.2020].

Solórzano, D. G. and Yosso, T. J. (2002) 'Critical race methodology: counter-storytelling as an analytical framework for education research', Qualitative Inquiry, 8, 1, 23-44.

Stevenson, J. (2012) Black and Minority Ethnic Student Degree Retention and Attainment, York: Higher Education Academy.

Stokes, P. and Martin, L. (2008) 'Reading lists: a study of tutor and student perceptions, expectations and realities', Studies in Higher Education, 33, 2, 113-25.

Thomas, S. P. and Jivraj, S. (eds.) (2020) Towards Decolonising the University: A Kaleidoscope for Empowered Action, Oxford: Counterpress.

TASO (2021) 'New research partnership: impact of HE curriculum reform on race equality gaps', Transforming Access and Student Outcomes, 21 January, https://taso.org.uk/news-item/new-research-partnershipimpact-of-he-curriculum-reform-on-race-equality-gaps/ [accessed: 25.03.2021].

Universities UK (UUK) and National Union of Students (NUS) (2019) Black, Asian and Minority Ethnic Student Attainment at UK Universities: \#closingthegap, London: Universities UK and National Union of Students.

University of Kent (n.d.) Diversity Mark Toolkit, https://blogs.kent.ac.uk/diversitymarktoolkit/ [accessed: 25.03.2021]. 